\begin{tabular}{|c|c|c|}
\hline $\begin{array}{c}\text { OPEN } \\
\text { JOURNAL } \\
\text { SYSTEMS } \\
\end{array}$ & $\begin{array}{c}\text { Available on line at Directory of Open Access Journals } \\
\text { Journal of Hyperspectral Remote Sensing v.10, n.1 (2020) 55-68 } \\
\text { www.periodicos.ufpe.br/revistas/jhrs }\end{array}$ & $\begin{array}{c}\text { Journal of } \\
\text { Hyperspectral } \\
\text { Remote Sensing }\end{array}$ \\
\hline "ISSN:2237-2202 & & "www.ufpe.br/jhrs \\
\hline
\end{tabular}

\author{
Amaury G. Pessoa Neto*, Ioná M. B. R. Barbosa ${ }^{* *}$ \\ *Mestrando em Engenharia Civil; Escola Politécnica de Pernambuco - Poli/UPE, Rua Benfica, 455, Madalena, Recife - PE - \\ Brasil. \\ Email: gouveia.amaury@gmail.com (Corresponding author) \\ *** Dra. em Engenharia Civil; Instituto Federal de Educação, Ciência e Tecnologia de Pernambuco - IFPE. \\ Email: ionarameh@recife.ifpe.edu.br
}

Received 3 May 2020; accepted 9 Jun 2020

\begin{abstract}
Bodies of water, like rivers, are ecosystems that perform ecological, economic and social functions and are directly related to the qualification of a city. However, with the disorderly and intense urban expansion this type of ecosystem has been the target of frequent anthropic attacks. Faced with this problem, it is essential to obtain updated data as a subsidy to analyze the dynamics of the areas that are destined to environmental conservation. This study aimed to identify, through geotechnology, changes in soil cover occurred in the years of 1974, 1997 and 2016 in the Water Body Conservation Zone (ZCA) of the protection zone of the Jaboatão river, located in the Jardim Barra de Jangada, municipality of Jaboatão dos Guararapes / PE. For this, orthophotocards were used, referring to the year 1974, and aerial images for the other periods, originating from the aerophotogrammetry service. These materials were manipulated in UTM coordinates in the Geocentric Reference System for the Americas (SIRGAS) through free software QGIS, where they were submitted to visual and supervised photointerpretation techniques. Based on this analysis, it was possible to obtain thematic maps with classes of use and land cover, where a significant increase in the anthropic area index was observed, totaling $53,46 \%$ of the studied region. Through the obtained results, the use of geotechnology as a viable and agile alternative to promote adequate environmental planning.
\end{abstract}

Keywords: anthropic attacks, geotechnology, environmental planning.

\title{
Análise espaço-temporal das mudanças no uso e cobertura do solo da zona de conservação de corpos d'água do loteamento Jardim Barra de Jangada, Jaboatão dos Guararapes/PE
}

\section{Resumo}

Corpos d'água, como os rios, são ecossistemas que desempenham funções ecológicas, econômicas e sociais e estão diretamente relacionados à qualificação de uma cidade. Entretanto, com a desordenada e intensa expansão urbana esse tipo de ecossistema vem sendo alvo de frequentes agressões antrópicas. Diante dessa problemática, torna-se indispensável a obtenção de dados atualizados como subsídio para análise da dinâmica das áreas que são destinadas a conservação ambiental. Este estudo buscou identificar, através de geotecnologia, as alterações da cobertura do solo ocorridas nos anos de 1974, 1997 e 2016 na Zona de Conservação de Corpos D’Água (ZCA) da faixa de proteção do rio Jaboatão, localizada no loteamento Jardim Barra de Jangada, município do Jaboatão dos Guararapes/PE. Para isso, foram utilizadas ortofotocartas, referentes ao ano de 1974, e imagens aéreas, para os demais períodos, oriundas de serviço de aerofotogrametria. Esses materiais foram manipulados em coordenadas UTM no Sistema de Referência Geocêntrico para as Américas (SIRGAS) através do software livre QGIS, onde foram submetidos a técnicas de fotointerpretação visual e supervisionada. A partir dessa análise, foi possível obter mapas temáticos com classes de uso e cobertura do solo, onde foi observado um expressivo aumento no índice de área antropizada, totalizando 53,46\% da região estudada. Através dos resultados obtidos, destaca-se a utilização da geotecnologia como uma alternativa viável e ágil para promover um planejamento ambiental adequados.

Palavras-chave: agressões antrópicas, geotecnologia, planejamento ambiental. 


\section{Introdução}

A urbanização é um fenômeno socioespacial que adquire formas de desenvolvimento de acordo com as especificidades da região e que tem sido associado a fatores como o crescimento econômico, a diminuição dos índices de fertilidade, uma maior expectativa de vida e deslocamentos geoespaciais (Cabral e Cândido, 2019; Sainte e Lammle, 2019). Conforme Vieira et al. (2017), o processo de urbanização no Brasil ocorreu com maior intensidade a partir da década de 1970, quando houve fluxo considerável de migrações de pessoas do campo para a cidade. No entanto, em muitas cidades brasileiras, esse fenômeno aconteceu de forma desordenada, acelerada e intensa, sem a fiscalização da gestão pública urbana e o ordenamento de dispositivos legais (Rocha e Schuler, 2016).

Para Silva et al. (2016), o fenômeno histórico da urbanização, frequentemente está associado à substituição de ambientes naturais ou seminaturais, por ambientes construídos, trazendo muitas vezes grandes prejuízos ambientais e culturais. Nesse contexto, Assis et al. (2014) afirmam que o processo de urbanização implica na forma atual de uso e ocupação do solo e tem provocado diversos tipos de impactos em níveis variados ao meio ambiente, tais como: a impermeabilização e erosão do solo, a poluição do ar e corpos hídricos, o desmatamento, a perda da biodiversidade, entre muitos outros. Para as autoras, esses impactos degradam o meio ambiente e diminuem a sua capacidade de regeneração e convivência salutar com a espécie humana.

Nas áreas destinadas a conservação ambiental, a compreensão da ocupação do espaço é essencial na prevenção da exploração dos recursos de forma desordenada (Lopes e Reuss-Strenzel, 2015). Pois, atualmente, essas regiões, que são extremamente frágeis, estão submetidas a grandes extensões de degradação devido à intensificação das pressões antrópicas sobre o ambiente e devido a essa fragilidade, qualquer alteração irá afetar a estabilidade geológica originando assim diversas perdas de recursos naturais (Moreira et al., 2015; Arana et al., 2018). Nesse contexto, transcende-se a necessidade do uso de técnicas para o auxílio da implantação de melhorias na questão ambiental.

Conforme Magalhães et al. (2014), o uso de geotecnologias tem representado uma importante contribuição para o monitoramento ambiental que, através de diversas técnicas, possibilita o mapeamento de solos e a identificação de impactos ambientais. Essas técnicas permitem identificar a origem dos aspectos modificadores do ambiente e a intensidade destas alterações, bem como os processos de degradação ambiental (Cechim Júnior e Silva, 2018). Além disso, concedem o estudo das inter-relações entre os dados econômicos, sociais e ambientais de forma integrada e georreferenciada, possibilitando a proposta de alternativas para diminuir impactos identificados no ambiente com o objetivo de contribuir para um desenvolvimento equilibrado e harmonioso do meio ambiente (Freitas et al., 2013; Magalhães et al., 2014).

A tecnologia do geoprocessamento permite ser utilizada para os mais diversos fins. Existem inúmeras metodologias desenvolvidas para serem aplicadas nos mais diferentes setores (Ruthes, 2012), sobretudo na análise de mudanças no uso e ocupação do solo de determinada região.

Nesse contexto, Nascimento e Fernandes (2017) mapearam e avaliaram os diferentes usos e ocupações do solo na bacia hidrográfica do igarapé da Prata, localizada no município de Capitão Poço - PA, nos anos de 2008, 2010 e 2012. Para isso, fizeram uso do sensoriamento remoto e geoprocessamento nas técnicas de interpretação das imagens, através de software de sistema de informações geográficas (SIG).

Mesquita et al. (2012) analisaram e mapearam os tipos de uso e ocupações da Área de Preservação Permanente (APP) da lagoa do Uruaú, localizada no município de Beberibe/CE. Esse estudo foi desenvolvido por meio da análise das modificações impressas na paisagem e de técnicas de geoprocessamento para elaboração do mapa de uso e ocupação da área.

Nogueira et al. (2019) analisaram os impactos ambientais, decorrentes do processo de arenização, sobre a bacia do Córrego Guanabara, município de Reserva do Cabaçal-MT. Eles utilizaram a geotecnologia e chegaram a constatar a evolução na extensão das áreas arenizadas entre os anos de 2005 e 2015.

Freitas et al. (2016) também demonstraram a importância na utilização da geotecnologia, através de sensoriamento remoto, realizando uma análise multitemporal em quatro décadas (1984 a 2015) do uso e cobertura do solo da Reserva Faunística Costeira de Tibau do Sul (REFAUTS), praia de Pipa, RN.

Buscando também evidenciar a importância da geotecnologia, o objetivo do presente estudo foi analisar as mudanças ocorridas na cobertura do solo da Zona de Conservação de Corpos d'Água da faixa de proteção do Rio Jaboatão no Loteamento Jardim Barra de Jangada, bairro de Barra de Jangada, município do Jaboatão dos Guararapes/PE, nos períodos de 1974, 1997 e 2016. 


\section{Material e métodos}

\section{Localização e caracterização da área de estudo}

O município do Jaboatão dos Guararapes está situado na região litorânea do Estado de Pernambuco e faz parte da Região Metropolitana do Recife (RMR), conforme mostra a Figura 1.

Segundo o IBGE (2020), Jaboatão dos Guararapes possui área de 258,694 km² que comporta uma população estimada de 702.298 habitantes, resultando numa densidade demográfica de 2.491,82 $\mathrm{hab} / \mathrm{km}^{2}$. O município está a $16,1 \mathrm{~km}$ da capital pernambucana, Recife, e suas principais vias de acesso são as rodovias BR-101, BR-232, BR-408, PE-007 e PE-008. Limita-se com Recife ao norte, Moreno a leste, São Lourenço da Mata a noroeste, Cabo de Santo Agostinho ao sul e com o Oceano Atlântico a leste. Limita-se com Recife ao norte, Moreno a leste, São Lourenço da Mata a noroeste, Cabo de Santo Agostinho ao sul e com o Oceano Atlântico a leste.
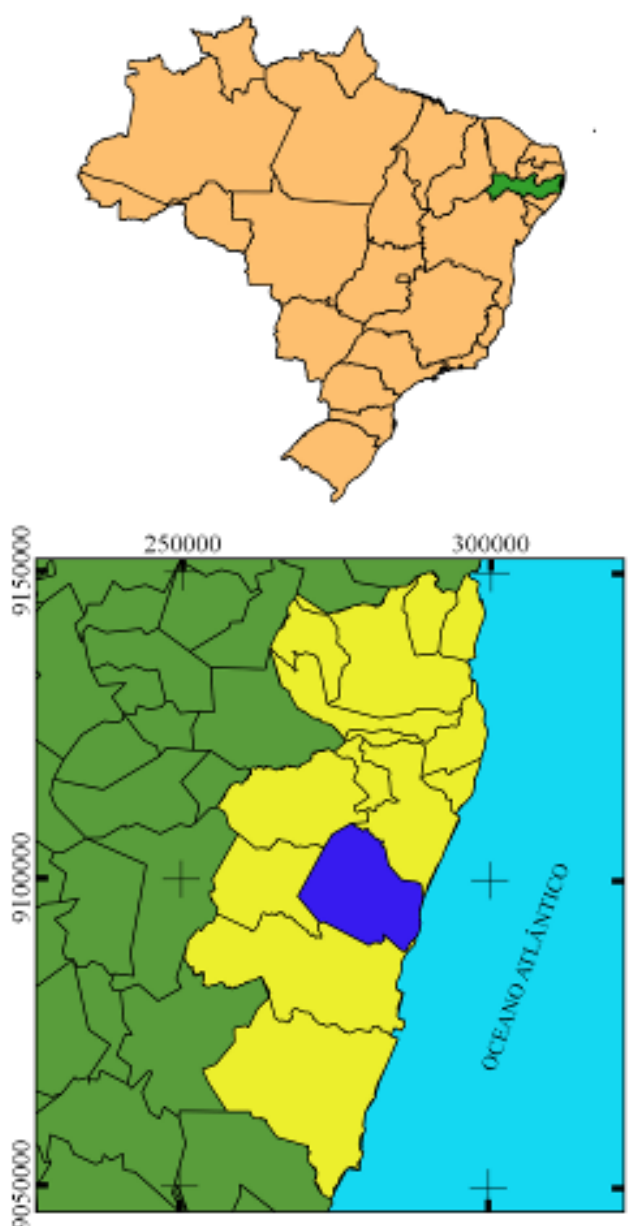

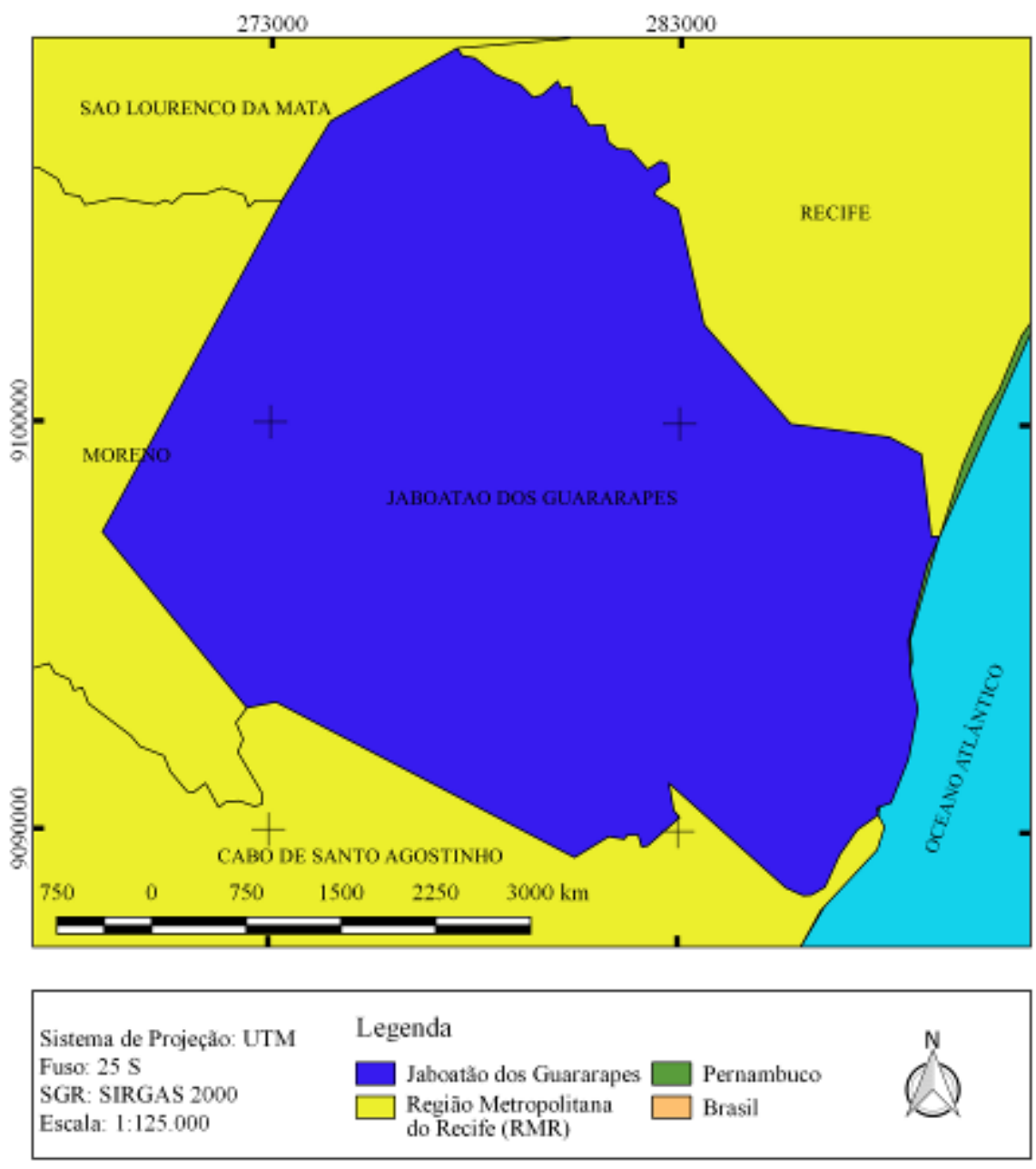

Figura 1 - Localização do município do Jaboatão dos Guararapes.

Jaboatão dos Guararapes, de acordo com o CPRM (1997), está localizado numa região que, segundo a classificação de Köppen, apresenta um clima tropical úmido (AMS'). Possui temperatura média anual de $26{ }^{\circ} \mathrm{C}$, mínima de $18{ }^{\circ} \mathrm{C}$ e máxima de $32{ }^{\circ} \mathrm{C}$. $\mathrm{O}$ ritmo de chuvas é definido por um período em que elas se desenvolvem entre os meses de março a agosto (outono-inverno), com pluviosidade máxima e mínima mensais de 270 e $140 \mathrm{~mm}$, respectivamente, com média anual de $1.500 \mathrm{~mm}$. A precipitação máxima ocorre durante o período de inverno.

O Loteamento Jardim Barra de Jangada é datado de 1951 (Figura 2) e está localizado no bairro de Barra de Jangada, ao sul da região costeira do município do Jaboatão dos Guararapes, definido entre as coordenadas UTM $286.993,881 \mathrm{mE}$ e $287.292,416 \mathrm{mE}, \quad$ e $\quad 9.090 .398,404 \mathrm{mN} \quad$ e $9.089 .992,674 \mathrm{mN}$. O referido loteamento tem por 
característica estar situado numa região de especulação imobiliária devido a exploração turística e a facilidade do acesso ao município do Cabo de Santo Agostinho, como apresenta a Figura 3. Limita-se por uma região de expansão imobiliária de alto padrão (Silva, 2013) a nordeste, pela foz do rio Jaboatão a sudeste e pela Estrada de Curcurana, que é uma importante via do município, a oeste.
A área de estudo é constituída pela Zona de Conservação de Corpos D'Água (ZCA) da faixa de proteção do Rio Jaboatão que é definida na Lei de Uso, Ocupação e Parcelamento do Solo do município (Lei $\mathrm{N}^{\circ}$ 972/2013) e está inserida no Loteamento Jardim Barra de Jangada, ocupando uma área de $8.744,80 \mathrm{~m}^{2}$, como retrata a Figura 4.

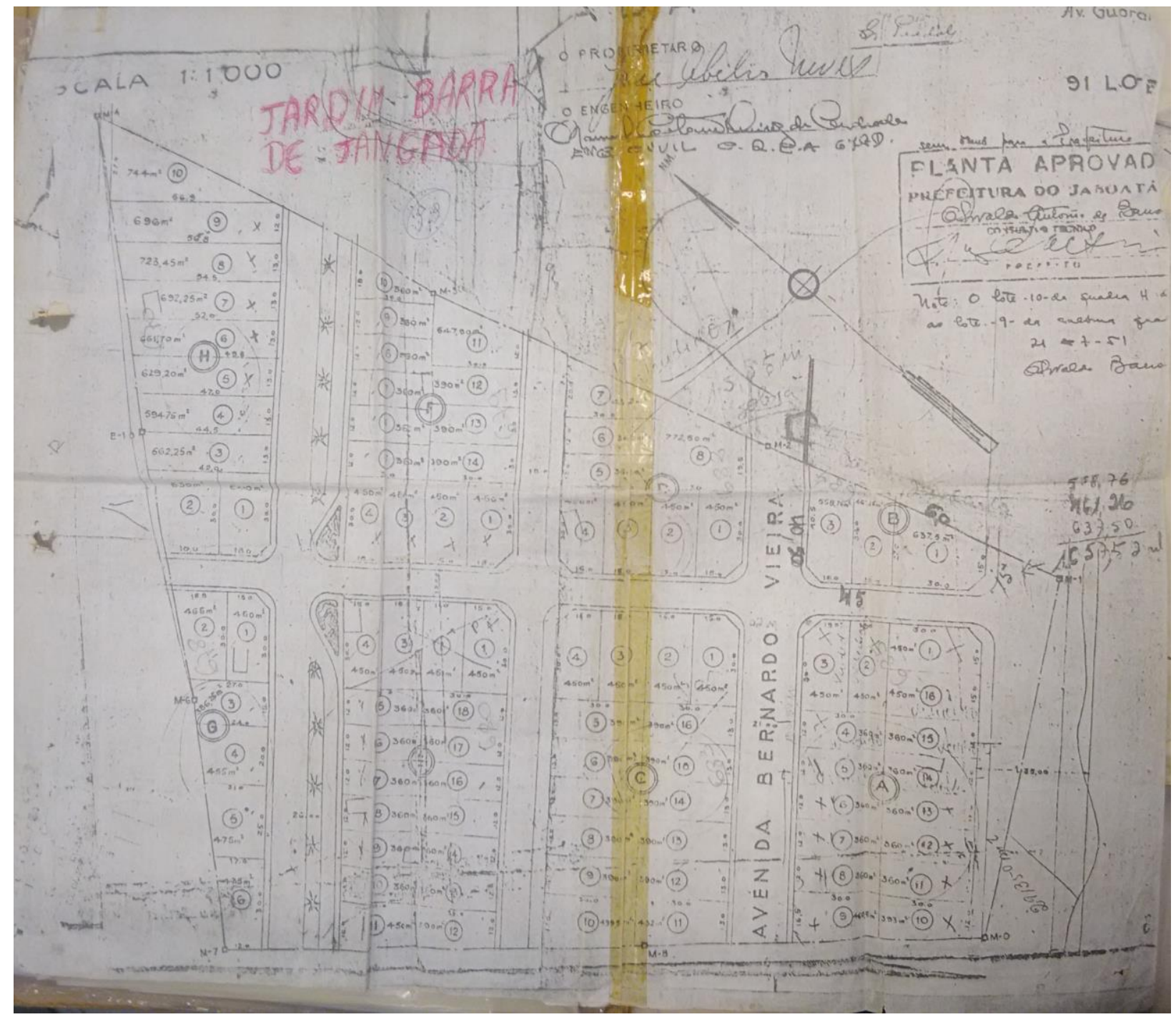

Figura 2 - Planta do Loteamento Jardim Barra de Jangada com carimbo de aprovação pela Prefeitura municipal datado de 21 de julho de 1951. 


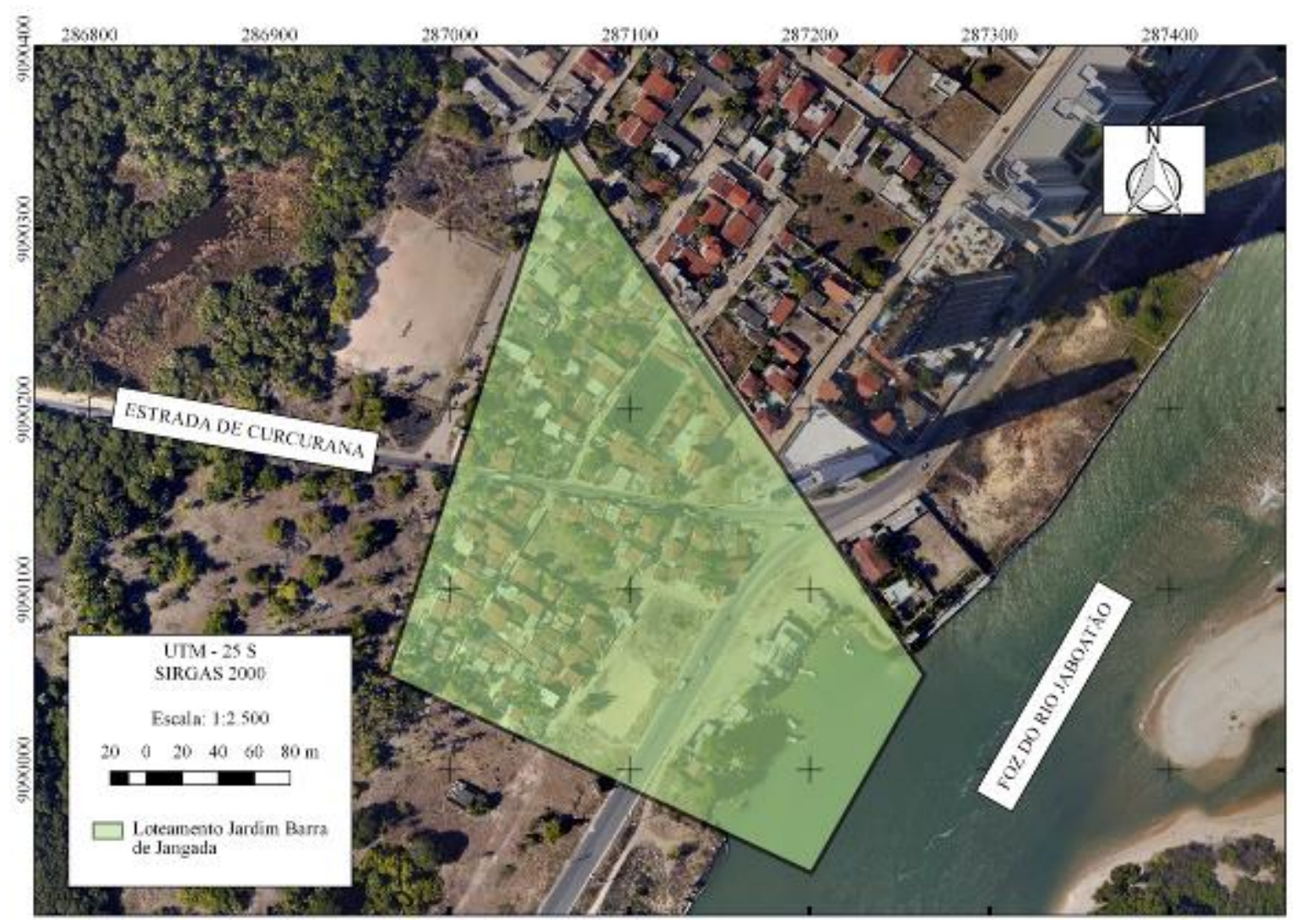

Figura 3 - Localização do loteamento Jardim Barra de Jangada.
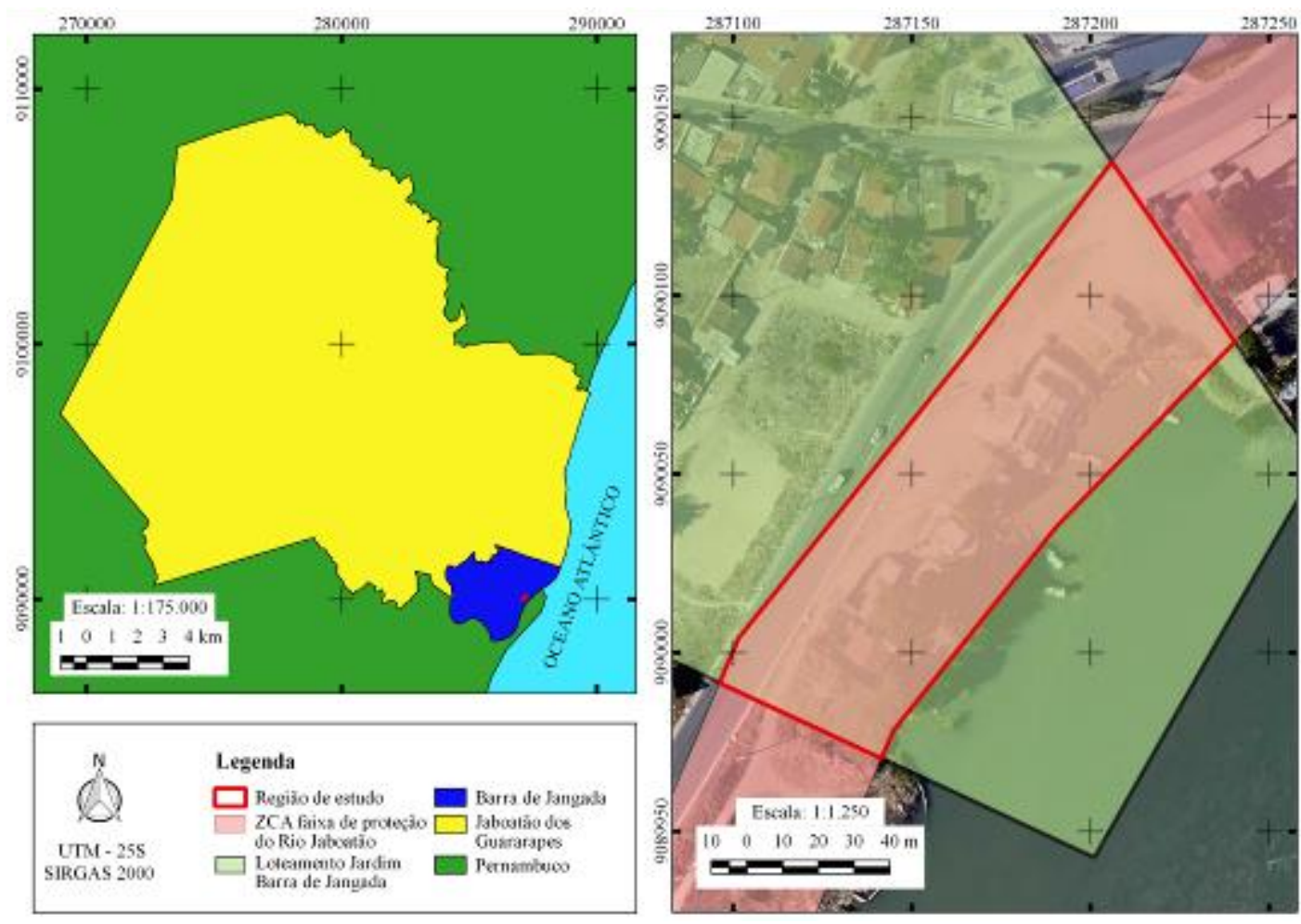

Figura 4 - Localização da ZCA da faixa de proteção do Rio Jaboatão inserida no Loteamento Jardim Barra de Jangada. 
A escolha dessa região foi motivada por ela possuir características físico-geográficas relevantes para a conservação da biodiversidade local e da qualidade climática e paisagística do município (Jaboatão dos Guararapes, 2008). Para López et al. (2012) esse tipo de região adquire importância por se tratar de um espaço natural intimamente ligado ao seu ambiente, uma vez que apresenta componentes essenciais para manter o biodiversidade e equilíbrio territorial.

\section{Metodologia}

A metodologia empregada neste trabalho pode ser agrupada nas seguintes etapas: aquisição de dados cartográficos da região de estudo em órgãos oficiais; delimitação da região do estudo com auxílio do software livre QGIS; identificação da cobertura do solo para os três tempos determinados ao estudo; realização de trabalhos de campo para verificação in loco do comportamento urbano desenvolvido na região e comparação com as análises obtidas nos mapas de cobertura de solo.

A primeira etapa deste trabalho consistiu na aquisição de elementos cartográficos da região de estudo para serem trabalhados embasados nos anos de 1974, 1997 e 2016. Esses dados foram disponibilizados pela Agência Estadual de Planejamento e Pesquisas de Pernambuco (CONDEPE/FIDEM) e pela Prefeitura do Municipal do Jaboatão dos Guararapes (PMJG), conforme apresentado na Tabela 1.

Tabela 1 - Relação dos elementos cartográficos adquiridos e utilizados na realização do estudo.

\begin{tabular}{ccccc}
\hline Fonte & Tipo de dado & Dado & Extensão & Período \\
\hline $\begin{array}{c}\text { Agência Estadual de } \\
\text { Planejamento e } \\
\text { Pesquisas de } \\
\text { Pernambuco }\end{array}$ & Raster & Ortofotocarta & JPEG & 1974 \\
& Raster & Imagem aérea & TIFF & 1997 \\
$\begin{array}{c}\text { Prefeitura Municipal } \\
\text { do Jaboatão dos }\end{array}$ & & Imagem aérea & TIFF & 2016 \\
Guararapes & Vetor & Restituição & 1997 \\
& & Lotereofotogramétrica & & 2016 \\
& & Bairros & shapefile & 2007 \\
& & de Jangada & 1951 \\
\hline
\end{tabular}

Através do software QGIS 2.18.22 a ortofotocarta foi georreferenciada com base na descrição de suas coordenadas. Em relação às imagens aéreas, datadas de 1997 e 2016, ambas já foram entregues georreferenciadas.

Esta proposta metodológica utilizou-se da construção de mosaicos multitemporais, georreferenciados que mediante processo analítico permite fazer avaliações temporais para o mapeamento sistemático da área, objeto da análise (Silva et al., 2016).

Após a inserção dos arquivos matriciais, foram adicionadas as seguintes camadas vetoriais shapefile: $\mathrm{o}$ bairro Barra de Jangada, o loteamento Jardim Barra de Jangada e a Zona de Conservação de Corpos D’água, pertencente a camada do zoneamento. A partir da interseção desses três elementos vetoriais, foi definida a região do estudo.

Todos esses materiais, vetoriais e matriciais, foram manipulados em coordenadas UTM no Sistema de Referência Geocêntrico para as Américas (SIRGAS).

As análises de comparação e fotointerpretação foram fundamentadas na observação das transformações ocorridas através das intervenções antrópicas nas áreas destinadas a conservação natural. Após a definição desse tipo de categoria, embasadas em análises visual e supervisionada, foram confeccionados os mapas temáticos de cobertura do solo da região de estudo para os anos de 1974, 1997 e 2016.

Na etapa da delimitação dos alvos em estudo, para o ano de 1974, foi criado no QGis uma camada, no formato shapefile, do tipo polígono para cada categoria fundamentada em análise visual. Para os anos de 1997 e 2016, as camadas foram elaboradas a partir de análise supervisionada, ou seja, através de restituição esteriofotagramétrica. Após serem definidos os polígonos, foi possível, então, calcular suas referidas áreas e analisar as modificações ocorridas em cada 
categoria na região de estudo. Para estas características observadas nas fotointerpretações foi elaborada uma tabela, para cada período estudado, no software Microsoft Excel (Versão 14.0) contendo os valores, em termos de medidas de superfície, do que foi alterado em função do tempo, anteriormente determinado, entre a quantidade de áreas construídas, áreas pavimentadas, corpos hídricos, solo exposto e vegetação.

Para corroborar na identificação das modificações ocorridas na região do estudo, realizou-se um trabalho de campo no local para reconhecimento da área e para auxiliar na definição das unidades de mapeamento. Foram fotografadas as situações de degradação ambiental mais relevantes, causadas por intervenção humana. Esses registros fotográficos foram georreferenciados e identificados na imagem aérea da região de estudo através de pontos.

\section{Resultados e discussão}

A partir da delimitação da área de estudo nas imagens aéreas foi elaborado um mapa temático, conforme retrata a Figura 5, evidenciando a dinâmica da ocupação ocorrida na região do estudo nos anos de 1974, 1997 e 2016.
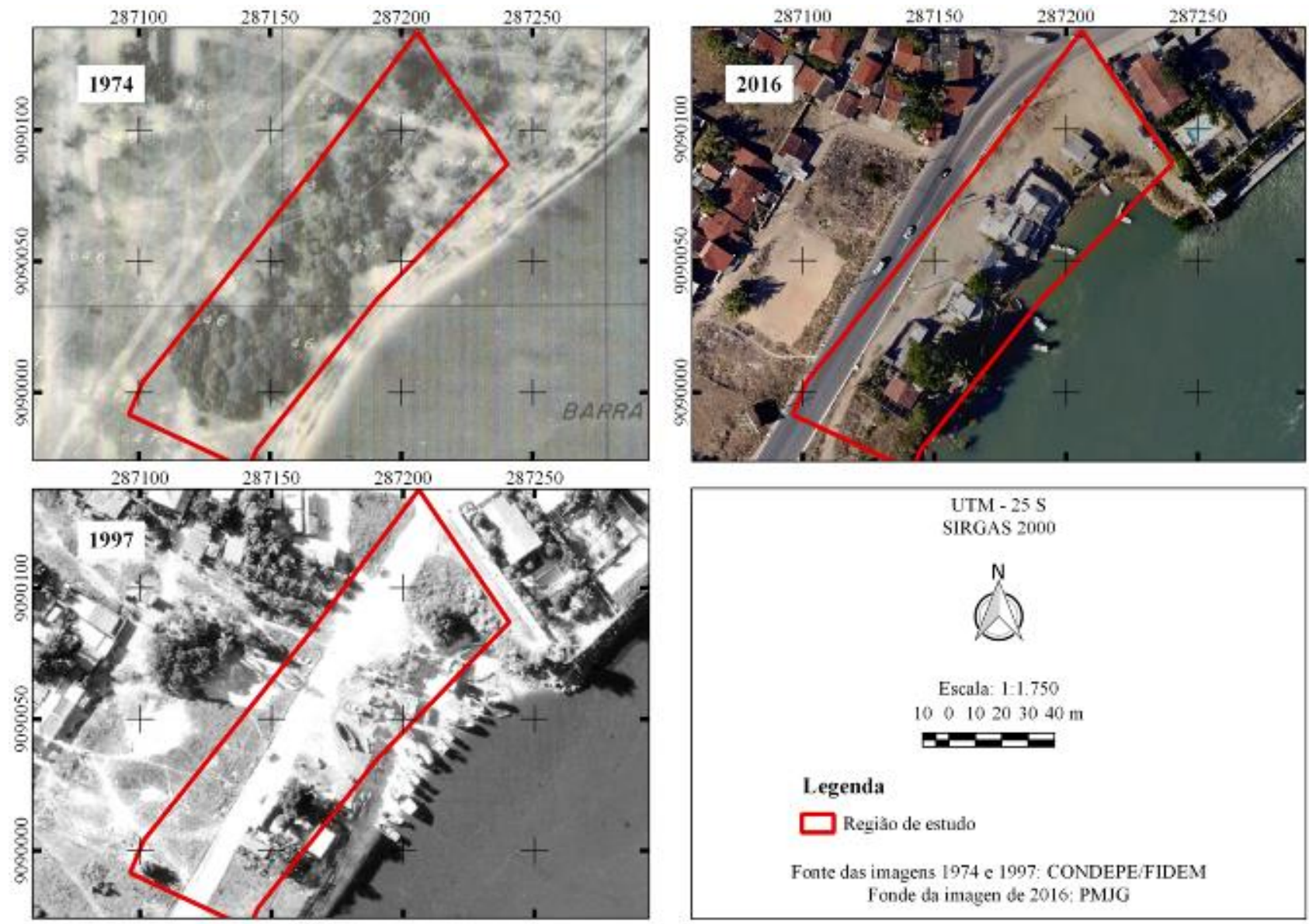

\section{UTM $-25 \mathrm{~S}$}

SIRGAS 2000

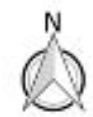

Escala: 11.750

$100 \quad 10203040 \mathrm{~m}$

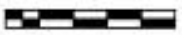

Legenda

Região de estudo

Fonte das imagens 1974 e 1997: CONDEPE/FIDEM Fonde da imagen de 2016: PMJG

Figura 5 - Análise comparativa da ZCA da faixa de proteção do Rio Jaboatão inserida no Loteamento Jardim Barra de Jangada entre os anos de 1974, 1997 e 2016.

Conforme a classificação dos usos identificados no mapeamento do ano de 1974 (Figura 6 e Tabela 2) evidencia-se a presença de apenas elementos naturais, isto é, vegetação e solo exposto, indicando que, durante esse período, a região não passava por intervenções antrópicas, sendo classificada por Silva (2010) como área rural. Pois, segundo seu estudo, não foram detectados pontos que pudessem ser classificados como formas de urbanização difusa e as raras comunidades que puderam ser observadas apresentavam tipologia rurais.

A vegetação e solo exposto ocupam a totalidade da área da região para o ano de 1974, sendo 89,02 e $10,98 \%$, respectivamente, o que equivale, aproximadamente, a 7784,80 e $960,00 \mathrm{~m}^{2}$. 


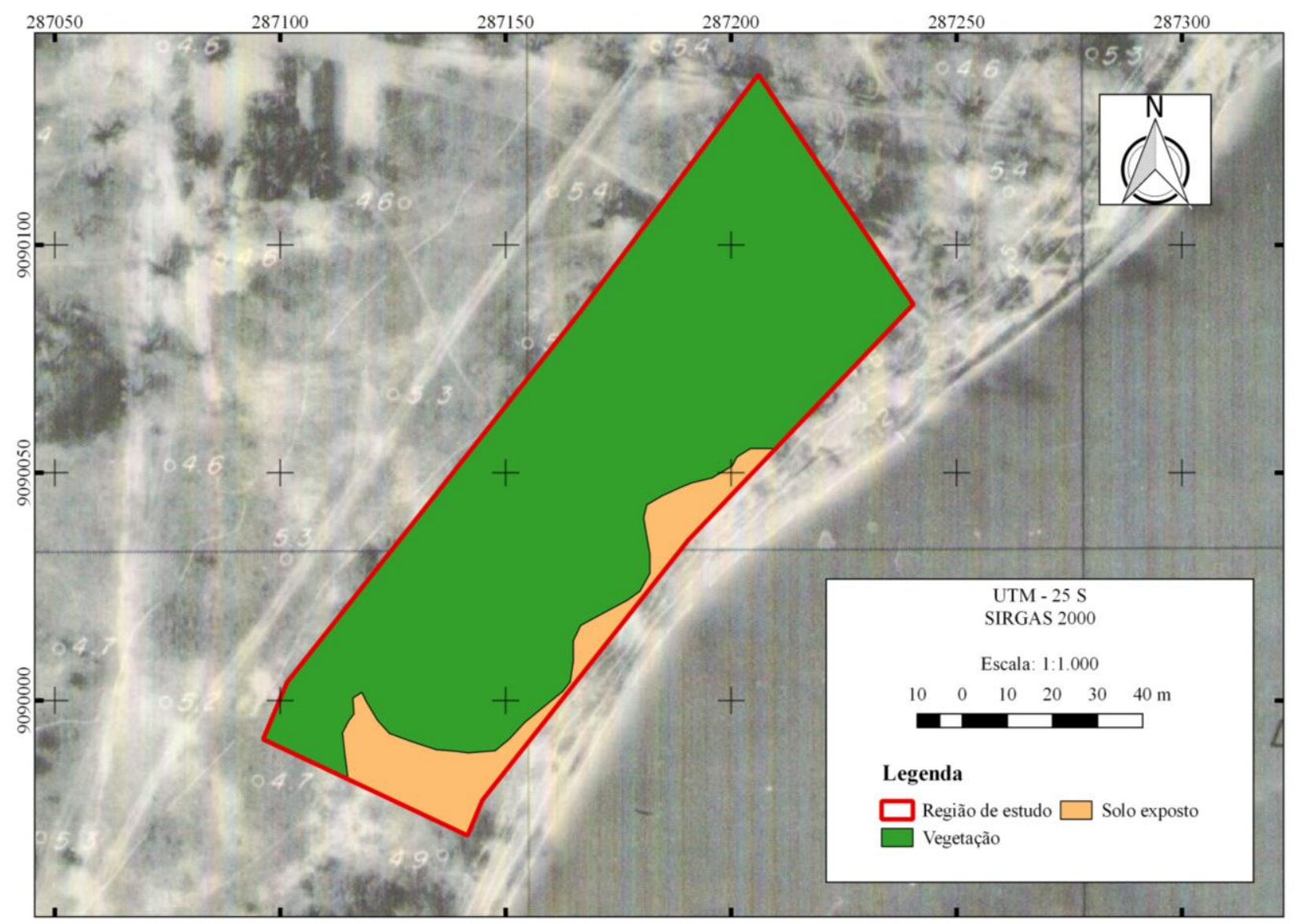

Figura 6 - Cobertura do solo da ZCA da faixa de proteção do Rio Jaboatão inserida no Loteamento Jardim Barra de Jangada no ano de 1974.

Tabela 2 - Classificação da cobertura do solo da ZCA da faixa de proteção do Rio Jaboatão inserida no Loteamento Jardim Barra de Jangada para o ano de 1974.

\begin{tabular}{ccc}
\hline Uso & Área $\left(\mathbf{m}^{2}\right)$ & Taxa Percentual $(\boldsymbol{\%})$ \\
\hline Vegetação & $7.784,80$ & 89,02 \\
Solo exposto & 960,00 & 10,98 \\
\hline Total & $8.744,80$ & 100,00 \\
\hline
\end{tabular}

Quando analisados os resultados de 1997 , apresentados na Figura 7, percebe-se o surgimento de algumas edificações na região do estudo. Essa área edificada é constituída por marinas que, segundo Silva (2013), foram construídas para facilitar a entrada e saída de embarcações de diversos portes, utilizadas para lazer e ou atividades pesqueiras. Esse comportamento é justificado através do estudo realizado por Silva (2010), onde o referido autor mostra que durante esse período a configuração sócio espacial da região já apresentava uma morfologia urbana bem mais complexa e bastante diferente daquela encontrada em 1974.
É possível observar, também, a presença de corpo hídrico que, conforme Silva (2013), surgiu no local devido ao desencadeamento de processos erosivos nas margens da foz do rio Jaboatão atingindo, sobretudo, a vegetação.

O solo exposto que, em 1974, era constituído por formação natural, em 1997 está atribuído às intervenções antrópicas, por se constituírem de caminhos e ruas que foram criados para facilitar o acesso às áreas edificadas. 


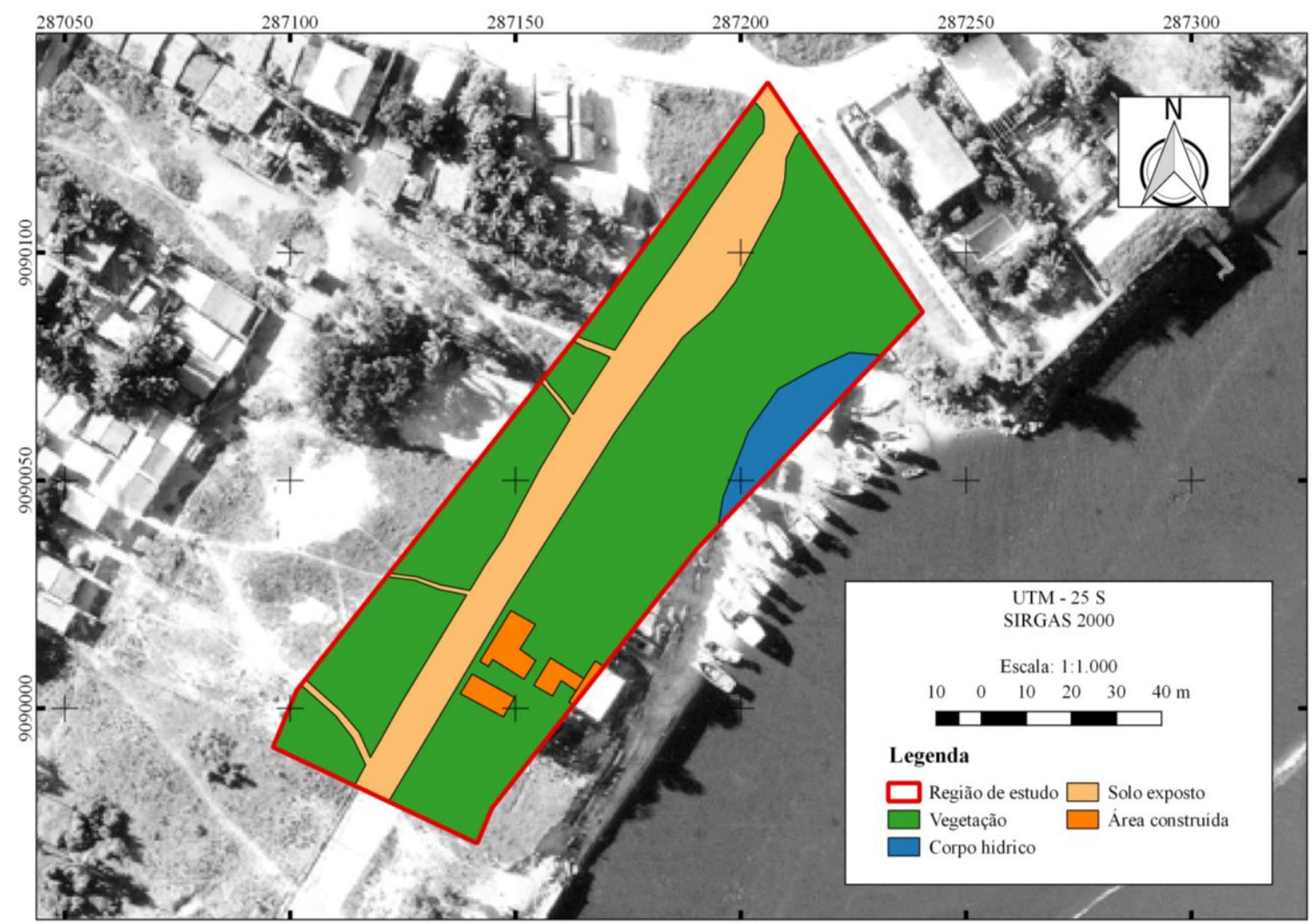

Figura 7 - Cobertura do solo da ZCA da faixa de proteção do Rio Jaboatão inserida no Loteamento Jardim Barra de Jangada no ano de 1997.

Os resultados demonstrados na Tabela 3 estabelecem as supracitadas modificações na configuração da área de estudo. As áreas antropizadas, que não existiam no ano de 1974, em 1997 passaram a representar $27,84 \%$ do total da área de estudo, sendo $2,44 \%, 21,04 \%$ e $4,36 \%$ destinadas a áreas construídas, solo exposto e corpo hídrico, respectivamente. Ao passo que as categorias relacionadas a antropização surgem, as demais diminuem. É o que pode ser observado na vegetação que, em 1974, apresentava 89,02\% e em 1997 passa a ter 72,16\% da área de estudo.

Tabela 3 - Classificação da cobertura do solo da ZCA da faixa de proteção do Rio Jaboatão inserida no Loteamento Jardim Barra de Jangada para o ano de 1997.

\begin{tabular}{ccc}
\hline Uso & Área $\left(\mathbf{m}^{\mathbf{2}}\right)$ & Taxa Percentual $(\boldsymbol{\%})$ \\
\hline Vegetação & $6.310,53$ & 72,16 \\
Corpo hídrico & 381,30 & 4,36 \\
Solo exposto & $1.839,62$ & 21,04 \\
Área construída & 213,35 & 2,44 \\
\hline Total & $8.744,80$ & 100,00 \\
\hline
\end{tabular}

Os resultados referentes a região do estudo no período de 2016 mostram como as intervenções antrópicas se intensificaram, como apresentado na Figura 8. De acordo com Silva (2013), esse processo de antropização está relacionado, principalmente, ao surgimento das edificações que margeiam a estrada que dá acesso a ponte Wilson Campos, mais conhecida como ponte do Paiva, pois ela facilita o acesso ao complexo de SUAPE diminuindo a distância entre a RMR em $40 \mathrm{Km}$.

Associado a esse cenário, Nogueira (2015) evidencia que empreendimentos edificados na 
proximidade da região do estudo, planejados para classes sociais de alta renda, trouxeram para orla de Barra de Jangada uma nova reprodução do espaço (verticalização), preenchendo-o com altas torres e uma ocupação desordenada do solo no entorno por classes sociais de baixa renda que não possui infraestrutura básica adequada, capaz de suportar o rápido
Conforme Costa (2019), esse adensamento construtivo observado no bairro de Barra de Jangada é, na realidade, consequência do processo de espraiamento da dinâmica construtiva litorânea, consolidada no Recife e nos demais bairros costeiros do Jaboatão dos Guararapes (Piedade e Candeias). crescimento urbano.

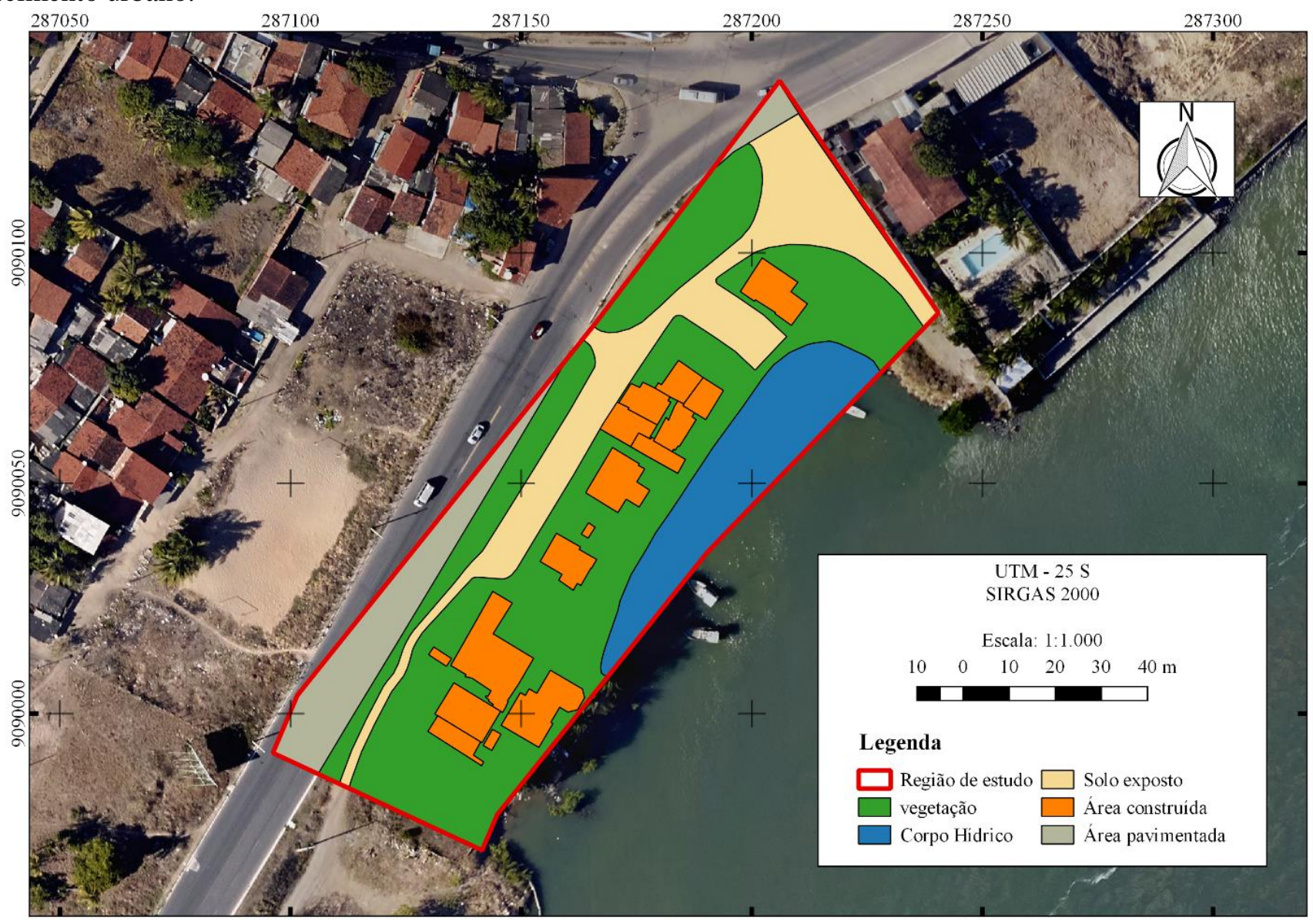

Figura 8 - Cobertura do solo da ZCA da faixa de proteção do Rio Jaboatão inserida no Loteamento Jardim Barra de Jangada no ano de 2016.

Pode-se perceber, através da Tabela 4, que a região estudada prevalece ocupada pela cobertura vegetal representada por coqueirais e vegetação rasteira, apresentando uma área de 4.067,74 $\mathrm{m}^{2}$, representando $46,52 \%$ de ocupação. No entanto, apenas essa categoria representa, neste estudo, áreas de conservação natural. Dentre as categorias que compõem as agressões antrópicas obteve-se os seguintes resultados:

- Corpo Hídrico: representado pelo rio Jaboatão. Essa categoria foi ocasionada pela intensificação dos processos erosivos na região e ocupa $12,87 \%$ da região do estudo, equivalendo a uma área de 1.125,05 m²;
- Área construída: ocasionada pela desorganizada e intensa expansão urbana, indicando uma área de $1.113,72 \mathrm{~m}^{2}$ e $12,74 \%$ de ocupação;

- Solo exposto: originado por desmatamento e pela definição de ruas e acessos às áreas edificadas, ocupando uma área de $1.609,52 \mathrm{~m}^{2}(18,41 \%)$;

- Área pavimentada: instituída para facilitar o tráfego dos veículos, sobretudo ao complexo de SUAPE, com uma área ocupada de 828,57 $\mathrm{m}^{2}(9,46 \%)$;

Somadas, essas categorias provenientes de antropização representam $53,48 \%$ de toda a região estudada. Sabe-se que, pelo fato dessa região ser de conservação ambiental, não deveria apresentar nenhum tipo de intervenção antrópica. 
Tabela 4 - Classificação da cobertura do solo da ZCA da faixa de proteção do Rio Jaboatão inserida no Loteamento Jardim Barra de Jangada para o ano de 2016.

\begin{tabular}{ccc}
\hline Uso & Área $\left(\mathbf{m}^{\mathbf{2}}\right)$ & Taxa Percentual $(\boldsymbol{\%})$ \\
\hline Vegetação & $4.067,74$ & 46,52 \\
Corpo hídrico & $1.125,05$ & 12,87 \\
Solo exposto & $1.609,52$ & 18,41 \\
Área construída & $1.113,72$ & 12,74 \\
Área pavimentada & 828,57 & 9,46 \\
\hline Total & $8.744,80$ & 100,00 \\
\hline
\end{tabular}

O gráfico apresentado na Figura 9 mostra a variação percentual do comportamento da região do estudo durante os períodos analisados, onde é possível verificar que as áreas referentes a agressões antrópicas superaram àquelas destinadas a conservação natural. Os dados obtidos evidenciam que houve uma diminuição da área de conservação natural de 8.744,80 $\mathrm{m}^{2}$ para $4.067,74 \mathrm{~m}^{2}$, isto é, uma perda de $53,48 \% \mathrm{em}$ um período de 42 anos, representando $46,52 \%$ da área total da região no ano de 2016.

Araújo (2017), em estudo na totalidade do bairro Barra de Jangada, verificou o crescimento urbano do local no período entre 1981 e 2013, através de análise multitemporal realizada por sensoriamento remoto. Nos 32 anos analisados, a autora constatou um aumento de área urbana de 289,23\%, destacando que o maior crescimento ocorreu nos anos entre 2002 e 2013, equivalendo a $115,32 \%$.

Menezes et al. (2018), em estudo semelhante, identificaram um elevado nível de urbanização na região costeira do município do Jaboatão dos Guararapes no ano de 2014. Os autores constataram um índice de 68,30\% relativos a intervenção urbana numa área de 1.397 ha, que equivale a área total da região do estudada.

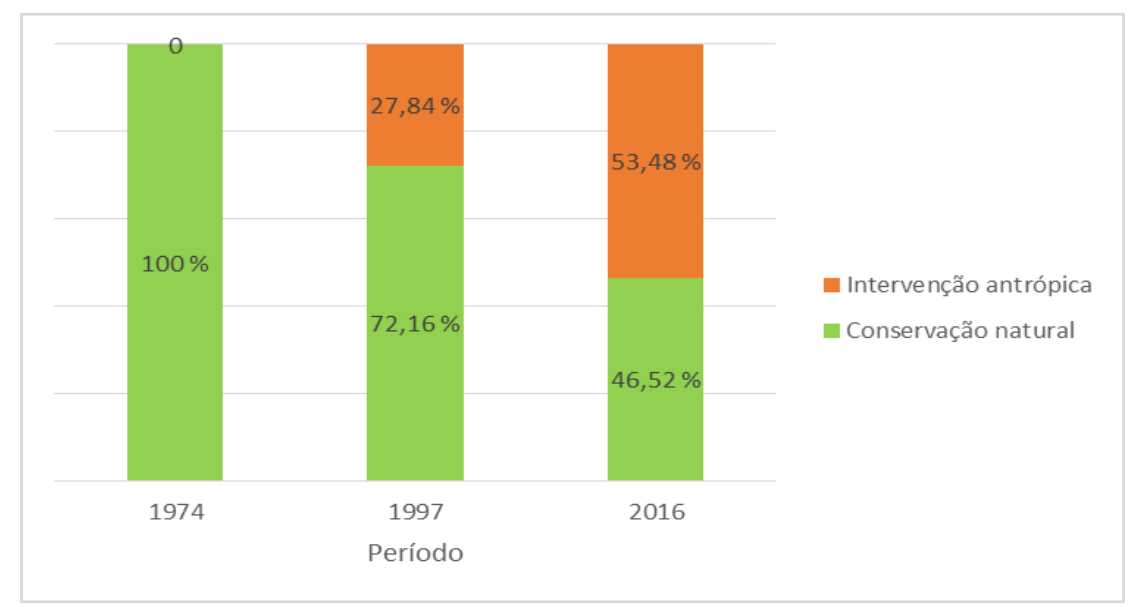

Figura 9 - Variação percentual do comportamento da ZCA da faixa de proteção do Rio Jaboatão inserida no Loteamento Jardim Barra de Jangada.

Esses resultados se tornam mais evidentes quando comparados aos registros fotográficos obtidos pela verificação realizada na região de estudo, como mostra a Figura 10.

Nos registros fotográficos foi constatado que grande parte das áreas edificadas se constituem por bares e restaurantes que se expandiram pela região de forma espontânea, ou seja, sem o devido planejamento ou gestão. A incidência desse tipo de atividade comercial nessa região é justificada por Delmiro e Silva (2018) que afirmam que a água exerce uma grande atração sobre a demanda turística, fazendo com que grandes números de pessoas se desloquem a grandes distâncias para ficar próximo ao mar. 


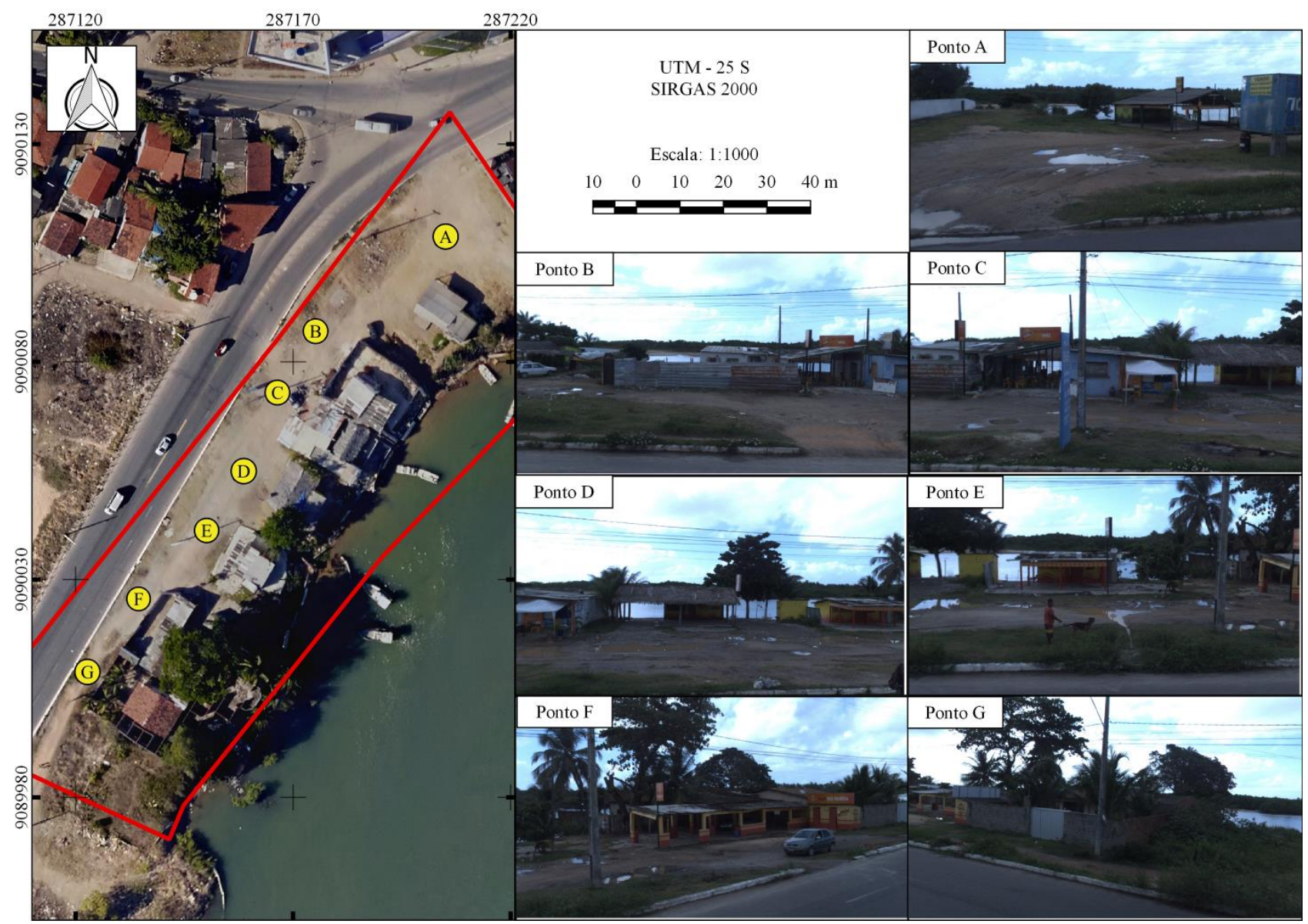

Figura 10 - Pontos analisados ao longo da ZCA da faixa de proteção do Rio Jaboatão inserida no Loteamento Jardim Barra de Jangada.

\section{Conclusões}

Através da geotecnologia foi possível obter dados de uso e ocupação do solo da região estudada para os anos avaliados (1974, 1997 e 2016) de maneira satisfatória, mostrando-se uma ferramenta eficiente, tanto em termos de economia de tempo quanto de recursos. Através dos resultados apresentados nesse estudo, foi possível identificar como a dinâmica da antropização seguiu na região, indicando que, da área total estudada, $53,48 \%$ sofre com interferências provocadas por esse tipo de intervenção.

Os dados apresentados contribuíram no despertar para os desafios atuais impostos à sustentabilidade ambiental. Os mesmos tornam-se efetivos para atuação da gestão municipal, considerando-se que através deles é possível promover um planejamento ambiental adequado, contribuindo para a melhoria da qualidade ambiental, reduzindo e fiscalizando impactos que podem ser causados pelo uso e ocupação irregulares em áreas prioritárias para preservação.

\section{Agradecimentos}

À Agência Estadual de Planejamento e Pesquisas de Pernambuco (CONDEPE/FIDEM) e à Prefeitura do Município do Jaboatão dos Guararapes (PMJG), pela colaboração no sentido de ceder os dados aqui apresentados.

\section{Referências}

Arana, A.R.A., Bezerra, J.P.P., Gonçalves, D.L., Leal, A.C., Osco, L.P., Ramos, A.P.M., 2018. Gestão das águas e planejamento ambiental: áreas de preservação permanente no manancial do alto curso do rio Santo Anastácio-SP. Revista Brasileira de Geografia Física 11, 674-686.

Araújo, F.E.de, 2017. Educação cartográfica: uso de imagens de sensoriamento remoto e mapas antigos no estudo da ocupação de Candeias e Barra de Jangada. Dissertação (Mestrado). Recife, UFPE.

Assis, J.M.O.de, Calado, L.deO., Souza, W.M.de, Sobral, M.doC.A., 2014. Mapeamento do uso e ocupação do solo no município de Belém de São 
Francisco-PE nos anos de 1985 e 2010. Revista Brasileira de Geografia Física 7, 949-959.

Cabral, L.doN., Cândido, G.A., 2019. Urbanização, vulnerabilidade, resiliência: relações conceituais e compreensões de causa e efeito. Urbe - Revista Brasileira de Gestão Urbana 11, 01-13.

Cechim Júnior, C., Silva, M.R., 2018. Análise multitemporal do uso do solo da microbacia do rio Sarandi no Sudoeste do estado do Paraná, Brasil utilizando imagens LANDSAT/TM. Ciência e Natura 40, e43.

Costa, H.B.da, 2019. Perspectivas de rearranjo socioespacial a partir da produção imobiliária de alto padrão no bairro de Barra de Jangada Jaboatão dos Guararapes - PE. Dissertação (Mestrado). Recife, UFPE.

CPRM. Serviço Geológico do Brasil, 1997. Atlas do meio físico do município do Jaboatão dos Guararapes - Estado de Pernambuco: Recife. Disponível: http://rigeo.cprm.gov.br/jspui/handle/doc/9038. Acesso: 20 jun. 2019.

Delmiro, K.L., Silva, C.deO., 2018. Turistificação e a questão ambiental na zona costeira do Estado de Alagoas, Brasil. Diversitas Journal 1, 66-75.

Freitas, E.P., Moraes, J.F.L., Peche Filho, A., Storino, M., 2013. Indicadores ambientais para Áreas de Preservação Permanente. Revista Brasileira de Engenharia Agrícola e Ambiental 17, 443-449.

Freitas, D.C.de, Silva, P.C.M.da, Lunardi, V.deO., Santos, J.E.A.dos, Lunardi, D.G., 2016. Uso e ocupação do solo na Reserva Faunística Costeira de Tibau do Sul (REFAUTS), Rio Grande do Norte, Brasil (1984 - 2015). Revista Brasileira de Geografia Física 9, 1880-1887.

IBGE. Instituto Brasileiro de Geografia e Estatística, 2020. IBGE Cidades: Jaboatão dos Guararapes. Disponível:

https://cidades.ibge.gov.br/brasil/pe/jaboatao-dosguararapes/panorama. Acesso: 9 jun. 2020.

JABOATÃO DOS GUARARAPES. Lei $\mathrm{n}^{\circ}$ 002, de 11 de janeiro de 2008. Institui o Plano Diretor do município do Jaboatão dos Guararapes e estabelece as diretrizes para a sua implantação, [2008]. Disponível: $\quad$ http://legis.jaboatao.pe.gov.br/leicomplementar/2009/00002/. Acesso: 20 jun. 2019.

JABOATÃO DOS GUARARAPES. Lei n ${ }^{\circ}$ 972, de 16 de novembro de 2013. Estabelece a Lei de Uso, Ocupação e Parcelamento do Solo do município do Jaboatão dos Guararapes, [2013]. Disponível: https://pt.scribd.com/document/235959793/Lei-9722013-Jaboatao-Luos. Acesso: 20 jun. 2019.
Lopes, E.R.doN., Reuss-Strenzel, G.M., 2015. Geoprocessamento aplicado à caracterização da ocupação de unidades de conservação - um olhar sobre a área de proteção ambiental de Guaibim, Bahia, Brasil. Revista de Geografia (UPFE) 32, 4359.

López, M.J., Bertoni, M., Testa, J., 2012. La importancia de las áreas naturales protegidas en el turismo litoral de la Provincia de Buenos Aires. Faces 18, 173-189.

Magalhães, I.A.L., Brito Júnior, L.R., Pena, F.E.daR., 2014. Use of Applied Geotechnology for Analysis of the Permanent Preservation Area - APP of Bico da Pedra Lake, in the Municipality of Janaúba, MG. Journal of Hyperspectral Remote Sensing 4, 153160.

Menezes. A.F., Pereira, P.S., Gonçalves. R.M., 2018. Uso de Geoindicadores para avaliação da vulnerabilidade à erosão costeira através de sistemas de informações geográficas. Revista Brasileira de Geografia Física 11, 276-296.

Mesquita, E.A., Cruz, M.L.B. da, Pinheiro, L.R.doÓ., 2012. Geoprocessamento aplicado ao mapeamento das formas de uso da terra na Área de Preservação Permanente (APP) da lagoa do Uruaú Beberibe/CE. Revista Geonorte 2, 1509-1518.

Moreira, T.R., Santos, A.R. dos, Dalfi, R.L., Campos, R.F.de, Santos, G.M.A.D.A.dos, Eugenio, F.C., 2015. Confronto do Uso e Ocupação da Terra em APPs no Município de Muqui, ES. Floresta e Ambiente 22, 141-152.

Nascimento, T.V.do, Fernandes, L.L., 2017. Mapeamento de uso e ocupação do solo em uma pequena bacia hidrográfica da Amazônia. Ciência e Natura 39, 170-178.

Nogueira, N.L.deM., 2015. Exercício de compreensão das transformações socioambientais em áreas costeiras urbanas à luz da análise multitemporal em diferentes escalas: bairro Barra de Jangada, Jaboatão dos Guararapes, Pernambuco. Dissertação (Mestrado). Recife, UFPE.

Nogueira, A.M., Tocantins, N., Salomão, F.X.deT., 2019. Degradação de áreas com processo de arenização na bacia do Córrego Guanabara, município de Reserva do Cabaçal-MT. Revista Brasileira de Geografia Física 12, 722-737.

Rocha, A.P., Schuler, C.A.B., 2016. Avaliação espaço temporal da suscetibilidade a movimentos de massa utilizando ortofotocartas e modelagem espacial multicritério na dinâmica de áreas de risco nas microrregiões do Jordão e Ibura, Recife-PE. Revista Brasileira de Cartografia 68, 1747-1770. 
Ruthes, K.R., 2012. Projeto piloto de um SIG para gerenciamento das atividades de georreferenciamento de uma empresa do setor florestal. Monografia (Especialização). Curitiba, UFPR.

Sainte, G., Lammle, L., 2019. O Estado e a política da urbanização: nova perspectiva para 0 desenvolvimento socioeconômico da cidade de Porto Príncipe (Haiti). GOT - Revista de Geografia e Ordenamento do Território 18, 179-208.

Silva, L.G.da, 2010. Tipologia das Dinâmicas de Urbanização na Franja Rural-urbana em Jaboatão dos Guararapes - Região Metropolitana do Recife. Dissertação (Mestrado). Recife, UFPE.

Silva, J.S.da, 2013. Desenvolvimento territorial e gestão de bacia hidrográfica: o caso da bacia do Rio Jaboatão, Pernambuco. Dissertação (Mestrado).
Recife, UFPE.

Silva, C.F.A.da, Barreto, E.P., Schuler, C.A.B., Ferreira, B., Melo, W.D.A., 2016. Evolução multitemporal do uso e ocupação do solo no entorno do campus da Universidade Federal Rural de Pernambuco Zona Oeste da Cidade do Recife. Revista Brasileira de Geografia Física 9, 319-333.

Vieira, R.dosS., Brito, J.F.G. de, Rocon, E.C., Modesto, D.E., 2017. Análise espaço temporal do crescimento da mancha urbana do bairro Colina de Laranjeiras - Serra/ES a partir da utilização de imagens Google Earth, in: Perez Filho, A., Amorim, R.R. (Org.), Os Desafios da Geografia Física na Fronteira do Conhecimento. Unicamp, Campinas, pp. 58305835. 